\title{
New Procedure in a New Situation: Short-term Effect of Renal Denervation for Resistant Hypertension in Case of a Patient Living with Pacemaker
}

\author{
Csaba A Dézsi ${ }^{1 *}$, Szabolcs Czuczor ${ }^{1}$, Béla Gartner ${ }^{2}$, Péter Bartek ${ }^{3}$, László Tamás ${ }^{4}$, Zsolt FI ${ }^{1}$ and Veronika Szentes ${ }^{1}$
}

${ }^{1}$ Department of Cardiology, Petz Aladár County Teaching Hospital, Hungary

${ }^{2}$ Department of Anesthesiology and Intensive care, Petz Aladár County Teaching Hospital, Hungary

${ }^{3}$ Department of Radiology, Petz Aladár County Teaching Hospital, Hungary

${ }^{4}$ Department of Vascular Surgery, Petz Aladár County Teaching Hospital, Hungary

\begin{abstract}
Aims: Renal denervation using the point-by-point application of radiofrequency (RF) energy delivered by the firstgeneration Symplicity system is effective in lowering office blood pressure however it is time-consuming. The Vessix Renal Denervation System with eight balloon-mounted bipolar electrodes shortens and simplifies the procedure. This has been the first in-human case examining the efficiency of reducing blood pressure and also the effect of RF energy in case of renal denervation on the normal functioning of pacemaker and the tolerability of the procedure in case of a patient living with pacemaker.
\end{abstract}

Materials and methods: The diabetic patient with a coronary artery disease had a baseline office systolic blood pressure $\geq 150 \mathrm{mmHg}$ and took four antihypertensive medications. She had a Biotronik Talos $\mathrm{S}$ pacemaker with a unipolar Biotronik PX 60 UP lead because of sick sinus syndrome however she was not dependent on pacemaker. We applied $30 \mathrm{sec}$. long RF treatments in the renal artery two times.

Results: The patients baseline systolic BP was $185 \mathrm{mmHg}$ which reduced by $30 \mathrm{mmHg}$ immediately after the denervation. The lowering of blood pressure was permanent during the 24-hour and four-months supervisions, despite the fact that we carried out the intervention only on one side. The radiofrequency energy did not have an impact on the normal functioning of the pacemaker during and after the intervention. It did cause less physical and psychological burden for the patient than a longer procedure.

Keywords: Refractory hypertension; Radiofrequency ablation; Renal denervation; Pacemaker; Hybrid therapy

\section{Introduction}

Occasionally it occurs that in spite of treating the patients with multiply combined antihypertensive medications, the blood pressure does not decrease to the normal level steadily. These patients, after excluding the possibility of secondary hypertension, belong to the group of therapy-resistant hypertension. In practice the treatment of these cases was not possible so far, consequently, they were exposed to the danger of stroke, heart attack, or renal complications. For this group of patients renal denervation gives a chance to maintain normal blood pressure by further applying of drugs $[1,2]$. The joint application of the invasive therapy and the traditional drug therapy [3] can be considered as hybrid therapy $[4,5]$. In this article we present a case the novelty of which, beside the hybrid therapy, is the experience gained concerning the effect of RF denervation of renal artery on the pacemaker functions. Several articles have been published about the percutaneous RF ablation of a variety of tumors, for instance of a hepatic neoplasm [6], and different kinds of RF antiarrhythmic therapies in connection with pacemakers, to clarify the question whether RF catheter ablation may cause pacemaker dysfunction due to electromagnetic interferences [712]. However, no article has been published yet about the experience in connection with renal denervation with balloon catheter in case of a patient living with pacemaker.

\section{Materials and Methods}

The 68-year-old woman's case history is the following: she has noninsulin dependent diabetes mellitus (NIDDM), coronary artery disease treated with a drug eluting stent (DES) implantation (2013) in her left anterior descendens (LAD) coronary. Her first VVI pacemaker was implanted in 2000 because of sick sinus syndrome (SSS). The generator was a Biotronik Kairos S and the lead was a Biotronik PX 60 UP. The lead was placed in the right ventricule and positioned in the apex. The generator was changed in 2011 to Biotronik Talos S because of discharge.

She has treatment-resistant hypertension for a long time and takes the following medications regularly: perindopril $10 \mathrm{mg} /$ day; nebivolol $7.5 \mathrm{mg} /$ day; lercanidipine $20 \mathrm{mg} /$ day; indapamid $2.5 \mathrm{mg}$ /day and gliclazide $60 \mathrm{mg} /$ day; acetylsalicyl acid $100 \mathrm{mg}$ /day; clopidogrel 75mg/ day; atorvastatin $60 \mathrm{mg} /$ day; pantoprazole $40 \mathrm{mg} /$ day and furosemide $40 \mathrm{mg} /$ week; kalium chloride 1 gram/week.

We excluded the secondary hypertension - included renovascular disease, hyperaldosteronism, glucocorticoid excess, pheochromocytoma, hyperthyroidism, hyperparathyroidism, obstructive sleep apnea, aortic coarctation, renal parenchymal disease, other illicit or prescribed medications that could have raised the patient's blood pressure- prior to renal denervation.

\section{Results}

The results of her 24-hour ambulatory blood pressure monitoring

*Corresponding author: Csaba A Dézsi, Department of Cardiology, Petz Aladár County Teaching Hospital, 9024 Győr, Hungary, Tel: 3696418244; E-mail: dcsa62@gmail.com

Received January 29, 2014; Accepted February 21, 2014; Published February 24, 2014

Citation: Dézsi CA, Czuczor S, Gartner B, Bartek P, Tamás L, et al. (2014) New Procedure in a New Situation: Short-term Effect of Renal Denervation for Resistant Hypertension in Case of a Patient Living with Pacemaker. J Hypertens 3: 140. doi:10.4172/2167-1095.1000140

Copyright: ( 2014 Dézsi CA, et al. This is an open-access article distributed under the terms of the Creative Commons Attribution License, which permits unrestricted use, distribution, and reproduction in any medium, provided the original author and source are credited. 
Citation: Dézsi CA, Czuczor S, Gartner B, Bartek P, Tamás L, et al. (2014) New Procedure in a New Situation: Short-term Effect of Renal Denervation for Resistant Hypertension in Case of a Patient Living with Pacemaker. J Hypertens 3: 140. doi:10.4172/2167-1095.1000140

Page 2 of 4

(ABPM) verified high values all day long (Figure 1) she had complained about having a headache very often.

The patient had a normal sinus rhythm, her heart rate was around $65 / \mathrm{min}$. The pacemaker's basic rate was $60 / \mathrm{min}$. and the hysteresis rate was $50 / \mathrm{min}$. These parameters resulted in $18 \%$ ventricular pacing ratio. The technical parameters were the following: the pulse amplitude was $2.4 \mathrm{~V}$ with pulse width $0.4 \mathrm{~ms}$, the pulse energy was $3.5 \mu \mathrm{J}$, its elective replacement interval (ERI) was 7 year 7 months, the sensitivity was $2.5 \mathrm{mV}$, the refracter period was $300 \mathrm{~ms}$ and the pacing and sensing polarity was unipolar. All parameters were tested before the procedure. Minimal R wave amplitude was $10.7 \mathrm{mV}$, ventricular threshold was 0.5 $\mathrm{V} / 0.4 \mathrm{~ms}$, battery impedance was $<0.3 \mathrm{Kohm}$, lead impedance was 498 Ohms.

The following parameters were programmed for the procedure: $4.8 \mathrm{~V}$ pulse amplitude, 0.75 pulse width and $5.5 \mathrm{mV}$ sensitivity. These values had led to $23.8 \mu \mathrm{J}$ pulse energy, and reduced the calculated ERI to 4 years 2 months. After the procedure the minimal $\mathrm{R}$ wave amplitude was $11.3 \mathrm{mV}$, ventricular threshold was $0.8 \mathrm{~V} / 0.4 \mathrm{~ms}$, the battery impedance was $<0.3 \mathrm{Kohm}$, and the lead impedance was $510 \mathrm{Ohms}$. The original pacemaker parameters were reprogrammed. We used the Biotronik ICS 3000 programmer to change the parameters.
For the penetration of the balloon catheter through the right femoral artery we used a $8 \mathrm{Fr}$ size Flexor Check-Flo Introducer catheter with High-Flex Dilator and Hydrophilic Coating (Cook Medical), a 0.018 " size guidewire and for the radiofrequency ablation the Vessix renal denervation system. It includes a low pressure (3 atm.) inflatable non-compliant over the wire balloon placed on the surface offset solid gold electrode pairs in helical pattern and all electrodes deliver energy simultaneously. The second part of the system is a bipolar RF generator with one button operation. The temperature was sensed and controlled at $68^{\circ} \mathrm{C}$ optimal for the delivery of thermal energy to adventitia to 3-4 mm deep for 30 seconds. The Graphical User Interface confirmed the size of electrode, the position of balloon catheter and displayed the key parameters of treatment time and the temperature. Bipolar technology obviates the need for the grounding pad.

We positioned a $5 \mathrm{~mm}$ diameter and $25 \mathrm{~mm}$ long balloon to the right renal artery as in the case of a standard percutan intervention (Figure 2). The technology requires only basic interventional skills. We applied $30 \mathrm{sec}$. long RF treatments in the renal artery two times (one distal and one proximal part) without overlapping the surfaces. The patient was given $5 \mathrm{mg}$ midazolam and $0.1 \mathrm{mg}$ phentanyl intravenously only one time and also $10.000 \mathrm{U} \mathrm{Na}$-heparin bolus before the operation.

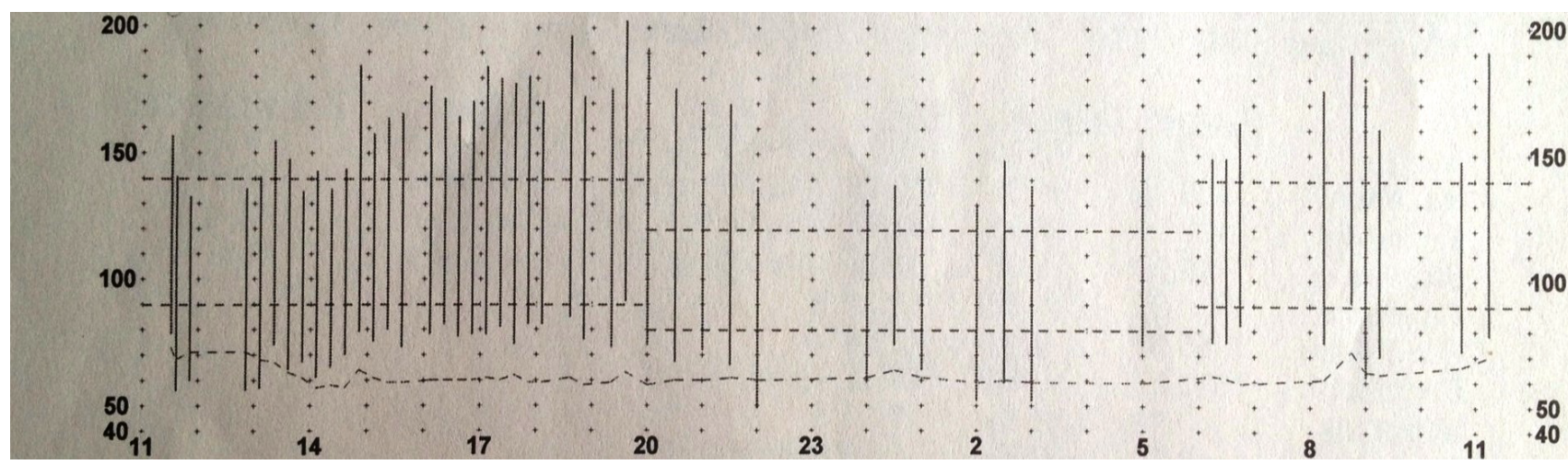

Figure 1: Before intervention. The vertical axis indicates time (in hours) and the horizontal axis indicates blood pressure (in mmHg) and heart rate (in beats per minute).

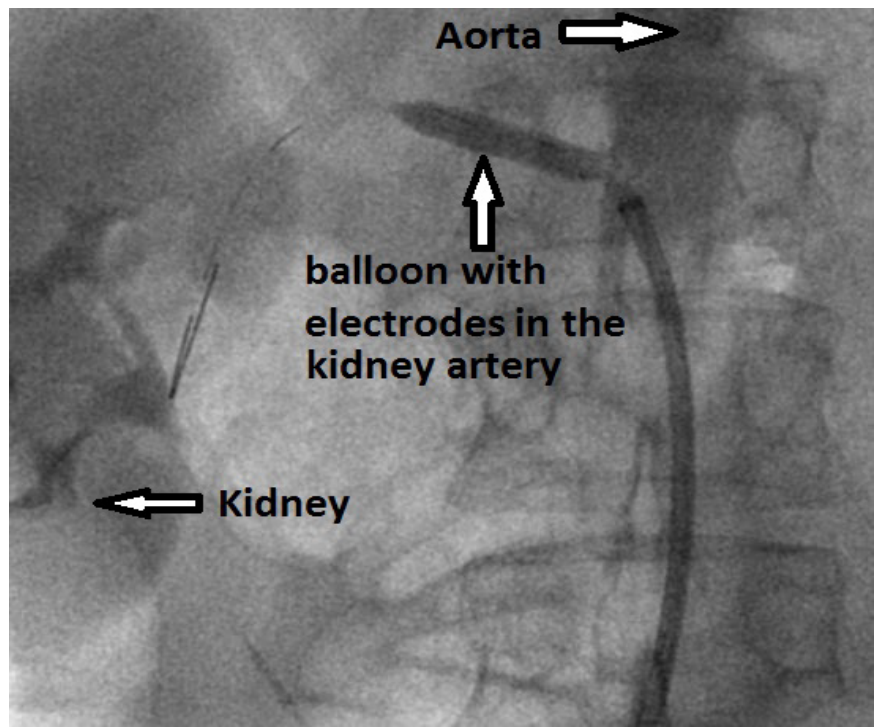

Figure 2: Renal denervation with the Vessix balloon catheter. The renal artery absolutely closed by the balloon and the electrodes are in contact with the vessel wall perfectly. 


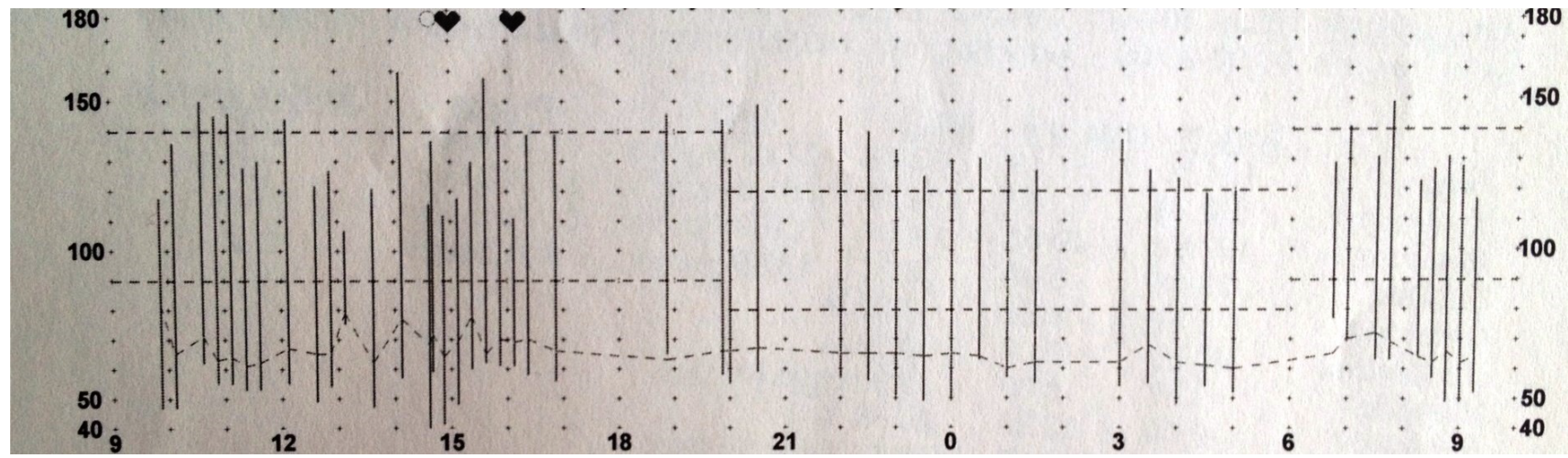

Figure 3: 24 hours after intervention. The vertical axis indicates time (in hours) and the horizontal axis indicates blood pressure (in mmHg) and heart rate (in beats per minute) The heart markers indicate the patient's short-term mild dizziness.

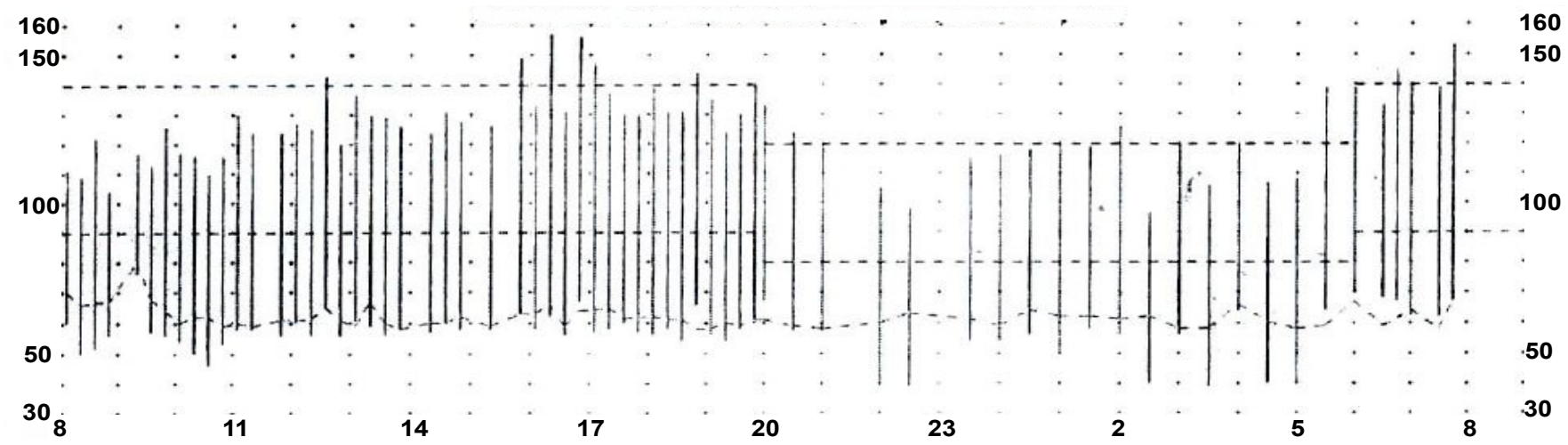

Figure 4: Four-months after denervation. The vertical axis indicates time (in hours) and the horizontal axis indicates blood pressure (in mmHg) and heart rate (in beats per minute). Based on the case history from 15:40 till 16:40 the patient performed physical activity.

\begin{tabular}{|c|c|c|c|}
\hline Blood pressure & & Systolic & Diastolic \\
\hline Mean $(\mathrm{mmHg})$ & BD: & 158 & 70 \\
\hline \multirow{2}{*}{ After denervation } & 24 hours & 133.5 & 56.5 \\
\hline & 4 Months & 123.8 & 55.7 \\
\hline Maximum $(\mathrm{mmHg})$ & BD: & 203 & 91 \\
\hline \multirow{2}{*}{ After denervation } & 24 hours & 160 & 77 \\
\hline & 4 Months & 157 & 76 \\
\hline Minimum $(\mathrm{mmHg})$ & BD: & 130 & 49 \\
\hline \multirow{2}{*}{ After denervation } & 24 hours & 107 & 40 \\
\hline & 4 Months & 97 & 39 \\
\hline $\mathrm{SDS}(\mathrm{mmHg})$ & BD: & 19.95 & 10.11 \\
\hline \multirow{2}{*}{ After denervation } & 24 hours & 12.19 & 7.46 \\
\hline & 4 Months & 13.57 & 7.56 \\
\hline Diurnal index & BD: & 9.32 & 15.7 \\
\hline \multirow{2}{*}{ After denervation } & 24 hours & 1.57 & 4.58 \\
\hline & 4 Months & 11.79 & 14.38 \\
\hline PTE (\%) & BD: & 91.46 & 3.42 \\
\hline \multirow{2}{*}{ After denervation } & 24 hours & 58.2 & 0 \\
\hline & 4 Months & 16.2 & 0 \\
\hline $\mathrm{HBI}\left(\mathrm{mmHg}^{*} \mathrm{~h} / 24 \mathrm{~h}\right.$ & BD: & 622.9 & 0.82 \\
\hline \multirow{2}{*}{ After denervation } & 24 hours & 160.58 & 0 \\
\hline & 4 Months & 37.35 & 0 \\
\hline
\end{tabular}

Table 1: The values of blood pressure, BD: before denervation; AD: after denervation; SDS: standard deviation score; PTE: percentage time of excess; $\mathrm{HBI}$ : hyperbaric impact.
After the procedure we closed the femoral arterial penetration area with a $8 \mathrm{Fr}$ size AngioSeal ${ }^{\mathrm{TM}}$ device and monitored the patient's blood pressure and circulation parameters for a few hours in our department before mobilization.

\section{Discussion}

The sudden falling of blood pressure can partly be explained by the effects of painkillers used during the intervention. However our periprocedural results were different from the ones experiences in the Symplicity studies. The blood pressure decreased significantly much sooner and it proved to be steady during the control ABPM examinations.

During renal denervation pacemaker sensing and pacing function was stable and reliable. No pacemaker dysfunction was detected. The patient complained only about a short mild abdominal pain. We could not place the balloon into the left renal artery because of an angulation traced at the beginning of the artery. Therefore the procedure carried out was a unilateral RF denervation. During both occasions of the delivery of radiofrequency energy the patient had only complained about a few seconds long, tolerable pain.

24 hours and 4 months after the procedure we put on her a 24 hour ABPM again which verified normal parameters almost during the whole day (Figure 3). The patient's heart rate had not changed, but her maximum blood pressure - both of systolic and diastolic - decreased 
Citation: Dézsi CA, Czuczor S, Gartner B, Bartek P, Tamás L, et al. (2014) New Procedure in a New Situation: Short-term Effect of Renal Denervation for Resistant Hypertension in Case of a Patient Living with Pacemaker. J Hypertens 3: 140. doi:10.4172/2167-1095.1000140

(Table 1) and her headache complaints ceased totally however she had complained two times about a short-term mild dizziness in the first 24 hours with being on the same medication as before. According to the four-month ABPM control the blood pressure of the patient did not rise above normal level (Figure 4). The blood test showed normal renal functions and the parameters of the pacemaker remained unchanged. The patient has no complaints.

\section{Conclusion}

This first in-human case of the Vessix renal denervation balloon system with a patient living with pacemaker, by successfully delivering $\mathrm{RF}$ energy to the renal arteries, has been proved to be a short and secure procedure. The RF energy in this case did not have an impact on the functioning of the pacemaker. This method of renal denervation used with balloon catheter results in immediate and effective decrease of blood pressure also in case of unilateral intervention. As a consequence of the renal denervation, while continuing the traditional drug therapy, permanent and efficient reduction of blood pressure can be achieved. The intervention cannot replace the drug therapy [12], however by excluding certain pathological nervous reflexes, helps keep the blood pressure in the normal range, thus preventing several cerebrovascular and cardiovascular complications.

\section{References}

1. Esler M, Krum H, Schmieder R, Bohm M (2013) Renal sympathetic denervation for treatment of resistant hypertension: two-year update from the Symplicity HTN-2 randomized controlled trial. J Am Coll Cardiol 61.

2. Symplicity HTN-1 Investigators (2011) Catheter-based renal sympathetic denervation for resistant hypertension: durability of blood pressure reduction out to 24 months. Hypertension 57: 911-917.

3. Dézsi CA (2014) Differences in the Clinical Effects of Angiotensin-Converting
Enzyme Inhibitors and Angiotensin Receptor Blockers: A Critical Review of the Evidence. Am J Cardiovasc Drugs.

4. Ormiston JA, Watson T, van Pelt N, Stewart R, Stewart JT, et al. (2013) Renal denervation for resistant hypertension using an irrigated radiofrequency balloon: 12-month results from the Renal Hypertension Ablation System (RHAS) trial. Eurolntervention 9: 70-74.

5. Légrády P, Nagy FT, Thury A, Bajcsi D (2012) Effect of bilateral catheterbased renal artery sympathetic denervation on blood pressure, therapy and baroreflex-sensitivity in a patient with resistant hypertension. Hypertonia ésNephrologia 16: 148-152.

6. Asensio EL, López TG, Guerrero MH, Orea AT, González AA, et al. (2009) Radiofrequency ablation of a hepatic neoplasm in a patient with an abdominal pacemaker. Cardiol J 16: 264-268.

7. Sadoul N, Blankoff I, de Chillou C, Beurrier D, Messier M, et al. (1997) Effects of radiofrequency catheter ablation on patients with permanent pacemakers. $J$ Interv Card Electrophysiol 1: 227-233.

8. Skonieczki BD, Wells C, Wasser EJ, Dupuy DE (2011) Radiofrequency and microwave tumor ablation in patients with implanted cardiac devices: is it safe? Eur J Radiol 79: 343-346.

9. Chang AC, McAreavey D, Tripodi D, Fananapazir L (1994) Radiofrequency catheter atrioventricular node ablation in patients with permanent cardiac pacing systems. Pacing Clin Electrophysiol 17: 65-69.

10. Lakkireddy D, Patel D, Ryschon K, Bhateja R, Bhakru M, et al. (2005) Safety and efficacy of radiofrequency energy catheter ablation of atrial fibrillation in patients with pacemakers and implantable cardiac defibrillators. Heart Rhythm 2: $1309-1316$.

11. Ellenbogen KA, Wood MA, Stambler BS (1996) Acute effects of radiofrequency ablation of atrial arrhythmias on implanted permanent pacing systems. Pacing Clin Electrophysiol 19: 1287-1295.

12. Hayes DL, Charboneau JW, Lewis BD, Asirvatham SJ, Dupuy DE, et al. (2001) Radiofrequency treatment of hepatic neoplasms in patients with permanent pacemakers. Mayo Clin Proc 76: 950-952. 